\title{
eCOti
DiAno
}

Revista Mídia e Cotidiano

ISSN: 2178-602X

Entrevista

Volume 15, Número 3, set./dez. de 2021

\section{Fernando Buen Abad Domínguez: epistemologia de combate e semiótica crítica}

\author{
Fernando Buen Abad Domínguez: Combat Epistemology \\ and Critical Semiotics
}

\section{Fernando Buen Abad Domínguez: Epistemología de Combate y semiótica crítica}

\author{
Marco SCHNEIDER ${ }^{1}$ \\ Marco Antônio BONETTI ${ }^{2}$
}

\section{Resumo}

O filósofo mexicano Fernando Buen Abad Domínguez é professor e diretor do Instituto de Cultura e Comunicação da Universidade Nacional de Lanús (Buenos Aires, Argentina). Nesta entrevista, realizada em setembro de 2021 por e-mail, Buen Abad Domínguez discorre sobre sua teoria da semiótica crítica, forjada na batalha epistemológica e ideológica mais ampla contra a dominação simbólica que trava dentro e fora da academia. Integrante de diversas associações internacionais, como a Rede de Intelectuais e Artistas Independentes em Defesa da Humanidade, fundada por Fidel Castro, Buen Abad entende que o problema da desinformação está relacionado à perpetuação da dominação de classe, cujo enfrentamento requer a democratização substantiva da comunicação. Mantivemos as respostas de Buen Abad Dominguez em seu idioma original para preservar a força e a potência de sua verve.

Palabras-clave: Dominação simbólica. Ideologia. Fake news.

\begin{abstract}
Mexican philosopher Fernando Buen Abad Domínguez is professor and director of the Institute of Culture and Communication of the National University of Lanús (Buenos Aires, Argentina). In this interview, carried out in September 2021 by electronic mail, Buen Abad Domínguez analyzes his theory of critical semiotics, forged in the epistemological and ideological battle against the symbolic domination within and outside the framework of the academy. Member of several international associations, such as the Network of Independent Artists and Intelectuals in Defense of Humanity,

\footnotetext{
${ }^{1}$ Professor do departamento de Comunicação da Universidade Federal Fluminense (UFF). Pesquisador do Instituto Brasileiro de Informação em Ciência e Tecnologia (Ibict). Pesquisador do CNPq (PQ-2). Bolsista do Nosso Estado Faperj. E-mail: marcoschneider@ibict.br. ORCID: 0000-0001-5053-9491.

2 Professor do departamento de Fundamentos e Contextos da Faculdade de Comunicação da Universidade Federal de Juiz de Fora (UFJF). Pós-doutorando do Ibict. Email: marcobonetti@id.uff.br. ORCID: 00000002-0130-0054.
} 
founded by Fidel Castro, Buen Abad Domínguez understands that the problem of disinformation is related to the perpetuation of class domination, whose confrontation requires na effective democratization of communications. We kept Buen Abad Domínguez's responses in their original language to preserve the strength and power of his verve.

Keywords: Symbolic domination. Ideology. Fake news.

\section{Resumen}

El filósofo mexicano Fernando Buen Abad Domínguez es profesor y director del Instituto de Cultura y Comunicación de la Universidad Nacional de Lanús (Buenos Aires, Argentina). En esta entrevista, realizada en septiembre de 2021 por correo electrónico, Buen Abad Domínguez comenta su teoría de la semiótica crítica, forjada en la batalla epistemológica e ideológica más amplia contra la dominación simbólica que se libra dentro y fuera de la academia. Miembro de varias asociaciones internacionales, como la Red de Intelectuales y Artistas Independientes en Defensa de la Humanidad, fundada por Fidel Castro, Buen Abad entiende que el problema de la desinformación está relacionado con la perpetuación de la dominación de clases, cuya confrontación requiere la democratización sustantiva de la comunicación. Mantuvimos las respuestas del Buen Abad Domínguez en su idioma original para preservar la fuerza y la fuerza de su brío.

Palabras-clave: Dominación simbólica. Ideología. Fake news.

\section{Presentación}

Fernando Buen Abad Domínguez es director de cine, graduado en la New York University, licenciado en Ciencias de la Comunicación, es máster en Filosofía Política y doctor en Filosofía. Miembro del Consejo Asesor de TeleSur, de la Asociación Mundial de Estudios Semióticos, de la Red de Intelectuales y Artistas en Defensa de la Humanidad y el Movimiento Internacional de Documentalistas, desarrolló actividades de investigación y docencia universitaria en México, Argentina, Venezuela, Bolivia, Ecuador y Estados Unidos. Es colaborador de Rebelión y otras revistas digitales. Fue presidente del Jurado del Festival Documental Três Continentes y miembro del jurado del Festival de Producción de Televisión Al Jazeera (Qatar 2006), entre otros. Fue Jefe del Departamento de Programas Culturales de XEIPN (canal de televisión del Instituto Politécnico Nacional) en la Ciudad de México. Ha escrito y dirigido 19 obras audiovisuales y cinematográficas en México, Houston, Nueva York y Argentina y es miembro de varias organizaciones artísticas y de investigación. Ha publicado más de 17 


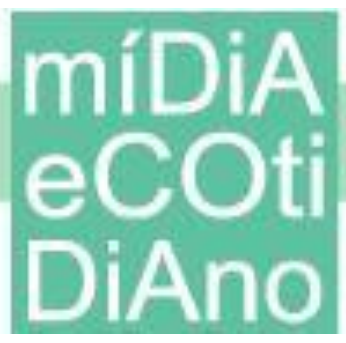

libros en México, Venezuela, España y Argentina, entre los que se destacan Filosofía de la Comunicación (2001), Filosofía de la Imagen (2003), Imagen, Filosofía y Creación (2004), Semiótica para la Emancipación (2009), Filosofía de Responsabilidad Socialista en la Comunicación (2012) y Filosofía del Humor y de la Risa (2013). En la siguiente entrevista se abordan asuntos teóricos y políticos de forma entrelazada, en torno al problema de la desinformación en su conjunto y, particularmente, de las fake news, las cuales son situadas por el entrevistado en el marco más amplio de la lucha de clases y la dominación simbólica.

\section{Entrevista}

M.SCHNEIDER e M.BONETTI: ¿Cuál es la diferencia entre su propuesta de una semiótica crítica y las corrientes tradicionales de la semiótica? ¿Cómo llegó a su formulación?

F.ABAD: Proponemos la creación de una corriente científica no subordinada. Proponemos el combate, la beligerancia epistemológica, la lucha contra la dominación simbólica y contra las "máquinas de guerra ideológica" monopolizadas por el capitalismo. Proponemos la batalla contra los paradigmas de la ideología de las clases dominantes. Aquí se entiende por semiótica una praxis para desactivar las máquinas de guerra ideológica que sea una herramienta de construcción hacia una semiosis emancipadora. Esto no es una "disciplina" para el regodeo de embrollos terminológicos, ni una plataforma para la contemplación - puramente descriptiva - sobre las "maromas" de la "semiosis" hegemónica que domestica conciencias. Entendemos que sobrevivimos en un campo semiótico minado y problemático. Entendemos que hay una disputa, a la que llamamos "disputa por el sentido", la lucha de clases en el campo de la semiosis. Interpelamos el "sentido comun" hegemónico de la permisividad absoluta para que un sector de una clase social se adueñe de la riqueza que produce la inmensa mayoría de las personas, ese es el sentido común aceptado, legitimado y legalizado. 
M.SCHNEIDER e M.BONETTI: ¿La reflexión filosófica sobre las nociones de verdad y de mentira es relevante para comprender las modalidades contemporáneas de desinformación?

F.ABAD: La verdad es un objeto de estudio crítico permanente, cuyo requisito indispensable es la participación de todas las miradas. La verdad es una entidad social malherida por la lucha de clases, porque mientras para unos el concepto de verdad se agota en las pruebas que tiene a la mano, hay sectores muy amplios de la población que, sin tener evidencias, resienten las consecuencias de algunas verdades hegemonizadas, esto todavía es muy abstracto. Quizá la verdad de todas las verdades, hoy por hoy, es la desigualdad, como es verdad que el capitalismo ha destruído a la humanidad y al planeta de manera incluso irreversible.

Falsificar la realidad es una actividad sistémica del capitalismo, una "religión" en la que las falacias son esencia y necesidad vital, de ellos, para poner fuera de la vista de la clase trabajadora, los modos y los medios de hurto contra el producto del trabajo y la enajenación de conciencias. No sólo invisibilizan la plusvalía, además nos embriagan con ilusiones o espejismos que hacen de las víctimas cómplices solidarios de sus verdugos. La producción de embrutecimientos, borracheras y anestesias simbólicas tiende a expandirse y a producir mutaciones aberrantes, afamadas porque son muy rentables. A cualquier costo. No nos cansaremos de repetirlo. El capitalismo es una fábrica de falacias.

Conquistar la verdad es un trabajo... es una lucha. La verdad no es una moneda que pueda darse y recibirse, sin más, en el mercado de la información. No nos cuenten que la verdad es "incognoscible", o subjetiva, porque el estado actual del conocimiento esté "limitado", mientras fabrican escondites, o mentiras retorcidas, para dificultar el camino del saber. La verdad se alcanza, y se defiende, con el esfuerzo militante del pensamiento y la acción críticos y organizados. Se alcanza en la dialéctica tensional entre el error y la certeza. En el debate capitaltrabajo. Al margen de reduccionismos. El problema de la verdad (tanto 
como la mentira) es un problema filosófico y humanista de nuestro tiempo. Sólo se resuelve en la praxis.

M.SCHNEIDER e M.BONETTI: ¿La mentira es un problema ético, político o epistemológico? ¿O atraviesa estos tres campos?

F.ABAD: Todo revuelto y programado. Una de las “joyas" más perfeccionadas y cotizadas, en el paraíso neoliberal globalizado, son las operaciones masivas de engaño. Armas de Distorsión Masiva que ha proliferado con gran velocidad y ubicuidad. Se desplazan globalmente con la protección, la unilateralidad discursiva, las pocas trincheras de réplica y las masas de corifeos que repiten, en simultáneo, cualquier ficción que les disfracen de noticias. Fake News a toda hora, con modalidades diversas, en horarios discriminados y efectos rentables. Con la bendición de los gobiernos neoliberales y un no pequeño público anestesiado bajo los placeres del engaño que se ahorran el trabajo de pensar y se envuelven en emociones mórbidas y morbosas.

$\mathrm{Y}$, mientras tanto, cuando los pueblos han encontrado fuerzas y caminos para derrotar al neoliberalismo, a sus engendrados empresariales y gubernamentales, a sus "máquinas de guerra ideológica" disfrazadas como "medios de comunicación", nos abruma una pandemia planetaria aprovechada jugosamente por el neoliberalismo y que no cesa en el maltrato burgués contra la humanidad. Nunca la avaricia de las cloacas financieras arremetieron con tanta furia falsaria.

El neoliberalismo es, patéticamente, una emboscada ideológica (en el sentido de la "falsa conciencia" que explicó Marx) desarrollada para disputar e imponer el "sentido común" de ciertos intereses capitalistas en su fase imperial. Es una máquina trituradora de derechos sociales adquiridos; una demoledora de los principios humanistas solidarios; una "picadora de carne humana" en los centros laborales, educativos y sanitarios; es una aplanadora de instituciones y una fenomenal maquinaria de humillaciones, depresiones y desmoralización... todo eso 
al servicio de un sector peligrosamente desquiciado por la usura, el individualismo más tóxico y la meritocracia supremacista de los amos en alianza con sus cómplices. Un infierno de corrupción y crimen que debe ser tipificado como etapa histórica "de lesa humanidad". La mezcla explosiva de neoliberalismo, Fake News y procesos electorales es una industria de la destrucción social altamente sofisticada.

M.SCHNEIDER M M.BONETTI: Continuando con el problema de la desinformación, ¿qué tiene de específico nuestro momento histórico?

F.ABAD: $\quad$ En la historia de la humanidade, em las disputas por el poder para las clases dominantes, está la mentira, con todas sus variedades complejas e interdependientes, rehaciendo dinámicamente sus significados formales, en multiplicidad de procesos, para "dar formas" a la mente, para organizar, jerarquizar, subordinar, disciplinar, instruir, enseñar... a conjuntos de relaciones sociales en condiciones históricas concretas. "Anestesiar" a los subordinados. Demorar sus rebeliones.

No es suficiente un retrato sobre el estado actual de la mentira con sus "fake news" se trata de generar herramientas y fuerzas para la emancipación de la producción de información falsaria, en su sentido ideológico opresor, amplio y contemporáneo; en su sentido jurídicoeconómico; en su sentido ético y estético; en su sentido instrumentaltecnológico; en su sentido "bio-genético", en el "neuro-científico" y en su sentido político organizacional, territorial e inmediato. No es una historia del "passado" es el presente mismo.

Una larga Historia recrudecida en el presente por una guerra económica, política y simbólica descomunal desatada por el capitalismo en su fase imperial, al mismo tiempo en crisis. Es imprescindible armarnos críticamente, luchar contra a los ejes teórico-metodológicos predominantes en la disputa global por el control de la información, a su praxis y contra el papel histórico de una concepción del poder que fabrica 
falacias para mantenerse. Eso no es nuevo aunque tenga novedades tecnológicas y creativas para mentirnos.

M.SCHNEIDER e M.BONETTI: La creciente cantidad de fake news en los últimos tiempos suele estar asociada a una supuesta polarización política. Sin embargo, pensamos que se trata más bien de un fenómeno vinculado al crecimiento de la extrema derecha, tanto en América Latina como en varias partes del mundo. ¿Cuál es su opinión acerca de esto?

F.ABAD: En las "Fake News" se establece claramente una fractura que corrompe el carácter objetivo y social de la verdad. Los comerciantes de falsedades pasan horas pergeñando qué estrategia del desfalco cognitivo es más funcional a sus intereses sin tener que someter sus "Fake" a la prueba de los hechos. Eso convierte al "consumidor de falacias" en un glotón de embutes dis-funcional y sofisticado. Mientras tanto, la producción de mentiras genera relaciones de producción que, para sostenerse, requiere de extinguir la verdad objetiva. Sitúa a los grupos sociales como animales de noria - como si fuese su destino - para motorizar el saber de lo falso. Desfigura las verdades objetivas y la práctica colectiva que las sustenta. El plan de la derecha y de la extrema derecha. Como en el nazi-fascismo. Aunque algunos se esmeran en reducir las "Fake News" al solo campo de los expertos en lo "comunicacional", para que pontifiquen diagnósticos y pronósticos, la dimensión del problema ha escalado latitudes de gravedad inusitada. ¿Están haciéndonos adictos a lo falso? Informarse es un derecho transversal a múltiples derechos y responsabilidades. Incluye a la educación, a la democracia, a la justicia... a la política. La información y su relación con la verdad no pueden ser marionetas del circo mercantil mediático, servil a la manipulación ideológica de algunos Gobiernos y empresarios oligarcas. Es inaceptable, se lo mire desde donde se lo mire, y cada caso de falacias mediáticas constituye una agresión a la realidad, a sus protagonistas y a la historia 
de los pueblos. Al modo de conocer y al modo de enunciar la realidad. Nada menos.

Aunque la moral burguesa tenga, para sí, un repertorio amplio de justificaciones a la hora de mentirnos. "El problema de si al pensamiento humano se le puede atribuir una verdad objetiva, no es un problema teórico, sino un problema práctico. Es en la práctica donde el hombre tiene que demostrar la verdad, es decir, la realidad y el poderío, la terrenalidad de su pensamiento. El litigio sobre la realidad o irrealidad de un pensamiento que se aísla de la práctica, es un problema puramente escolástico" (Marx).

La demolición de la verdad objetiva, se genera para negar la posibilidad de conocer el mundo y con ello la posibilidad de transformarlo. Atenta contra el derecho humano fundamental de crear condiciones mejores de existencia y desarrollo de capacidades, sin límite, gracias al goce de las riquezas naturales y las del producto del trabajo. Hasta ese punto la pandemia de "Fake News" intoxica la vida y las culturas. Es escandaloso. Entre las agresiones perpetradas por las máquinas de falacias mediáticas, que desempeñan un papel considerable, están los tipos de quiebres decisivos en el punto de vista de la vida que convierte al "auditorio" en holgazán sin pensamiento crítico y lo reduce (a los ojos de la burguesía y sus cómplices) en inútil, incómodo e impertinente. La pandemia de falacias aplasta al raciocinio libre y lo hace adicto a cualquier chatarra idealista; la adicción a las falacias aplasta todo lo que de ingenioso o profundo tiene el pensamiento crítico.

Por lo general las "Fake News" son extravagancias de la irracionalidad que, como todas las extravagancias, desfiguran a la experiencia. Hay quienes borran con falacias mediáticas la propia vivencia y la sepultan bajo los escombros del "sinsentido" común hegemónico. Despojados de nuestros derechos, mutamos y nos hacemos parásitos de generalizaciones abstractas y especulaciones subjetivas que obran como "verdades" placebo. Es la burocratización de la verdad. 
Despojarnos del derecho a informarnos no sólo es privarnos de "datos", es sepultar una necesidad social que reduce el acto de informar al capricho convenenciero de una guerra ideológica alienante. Eso implica una ofensiva contra la conciencia emboscada con una realidad deformada, desfigurada, desinformada. Es un fraude de punta a punta. No es una "omisión" más o menos interesada o tendenciosa...no es una "falla" del método; no es un accidente de la lógica narrativa; no es un incidente en la composición de la realidad; no es una "peccata minuta" del "descuido"; no es una errata del observador; no es miopía técnica ni es, desde luego, "gaje del oficio". Es lisa y llanamente una canallada contra el conocimiento, un delito de lesa humanidad. Es como privar a los pueblos de su Derecho a la Educación.

M.SCHNEIDER A M.BONETTI: ¿Qué iniciativas en curso para combatir la desinformación usted destacaría y qué queda por hacer?

F.ABAD: Democratizar la comunicación comenzando por su democracia interna. No es difícil estar de acuerdo en defender la "democracia", tampoco es difícil acordar la importancia de perfeccionarla, ampliarla, profundizarla, justamente con métodos democráticos. Lo difícil es hacerlo, y la historia reciente de los pueblos que la aceptan da pruebas claras de las distancias entre los dichos y los hechos. Eso enfrenta al problema, democrático también, de trasparentar el financiamiento de la política, hacerla transparente a la ciudadanía, de manera efectiva y participativa, a todos los ciudadanos. Democratizar, pues. el financiamiento de la política es transparentar el financiamiento de la comunicación toda.

De manera desigual y combinada, con avances y retrocesos, la democracia que goza de "buena fama" no siempre ha servido para el desarrollo real de los países. Aunque se acepta que los sistemas políticos de América Latina han logrado retrotraer la "época de las dictaduras" eso no ha impedido la comisión de golpes de estado y en lo que va del siglo XXI contamos ya con varios en la región. Los ciudadanos y ciudadanas 
reconocen ser demócratas casi exclusivamente para períodos electorales, espasmódicamente, el resto de la vida pasa de espaldas a la democracia en las casas, las oficinas, las fábricas, las aulas... donde es imperceptible la práctica democrática. Mandan los jefes sin consultar a las mayorías.

No es sólo asunto de "mantener las reglas del juego" en el tiempo sino de perfeccionarlas. ¿Cuántas personas ejercen efectivamente su derecho a participar democráticamente de comunicación y de la información. ¿Qué controles reales hay sobre los publicistas y las empresas mediáticas que han probado ser influencia decisiva en muchos procesos electorales y en muchas estructuras democráticas. Qué democracia existe al interior de esas estructuras? Democratizar los modos de producción en comunicación y las relaciones de producción.

M.SCHNEIDER e M.BONETTI: ¿Cómo puede el pensamiento de Marx ayudarnos a afrontar este conjunto de problemas?

F.ABAD: $\quad$ En la práctica cotidiana de mi trabajo pretendo que la Semiótica sirva para acercarnos, rápido, ese momento, que pensó Marx, para terminar con el modelo opresor-oprimido y tengamos otras realidades, otras verdades, otros valores para poner en común y otras formas de relacionarnos y de producir. Todo eso está por construirse no dogmáticamente. Urge afianzar el modo de poner en común, la posibilidad de que todos vivamos en condiciones de igualdad, y no solamente "igualdad de oportunidades", sino también en igualdad de condiciones. El método de Marx es de gran ayuda.

Tengo em mi escritorio una buena cantidad de anotaciones hacia una Semiótica marxista. Perdónese lo pretencioso. ¿Es posible tal cosa? ¿En dónde dijo, sugirió o indujo Marx algo que habilite a endilgarle una Semiótica? Creo que es necesario interpelarnos sobre las herramientas de producción sígnica, sus modos de producción y relaciones de producción de signos. Com que médios y modos se impone "La ideología de la clase dominante" que estudiaron Marx y Engels. Por ejemplo: la mercancía 
que sintetiza el "sentido" del sistema que la produce, síntesis debe hacerse visible en todas sus dimensiones y, para eso, debe servir la Semiótica también.

Se trata de intervenir, ayudados por el método de Marx, para generar una herramienta de doble uso que, por una parte, desmantele aparatos de dominación simbólica (o sígnica) y por otra parte sin disociarse, ayude a organizar un modo emancipador de producir sentido emancipado y emancipador. Enfrentar una tarea ardua. A la, ya acosada por calumnias sin freno, metodología de Marx le sumamos la, no poco obscurantista andanada terminológica, que acosa a la Semiótica y la convierte en inexpugnable y odiosa. Creo que de la mano de Marx se perfecciona la manera de luchar contra todo aquello que denote y connote, bajó cualquier recurso o emboscada, la ofensiva de clase para convencer a los "esclavos" de ser "felices" dándole la razón a su amo, cuidando sus ideas y propiedades y atesorando la ideología del opresor como la máxima herencia para su prole. Pero, principalmente, contribuir al desarrollo de denotaciones y connotaciones, producción de signos y relaciones de producción, que además de emancipadas sean emancipadoras hacia una semiosis revolucionaria como estrategia indispensable para, además de librarnos de toda canallada opresiva dispónganos de mentalidades y semiosferas en rebelión permanente.

No se puede consolidar un poder social emergente sin una corriente de sentido capaz de superar al "sentido común" hegemónico. Siempre y cuando el poder económico dominante también sea sometido a disputa y sea derrotado. Concluido. 